\title{
Layered Lanthanide Sulfophosphonates and Their Proton Conduction Properties in Membrane Electrode Assemblies
}

Montse Bazaga-García, ${ }^{\dagger}$ Inés R. Salcedo, ${ }^{\dagger}$ Rosario M. P. Colodrero, ${ }^{\ddagger}$ Konstantinos Xanthopoulos, ${ }^{\S}$ Didier Villemin, ${ }^{\perp}$ Norbert Stock, ${ }^{\| \odot}$ Mar López-González, ${ }^{\#}$ Carmen del Río, ${ }^{\#}$ Enrique R. Losilla, ${ }^{\dagger}{ }^{\dagger}$ Aurelio Cabeza, ${ }^{\dagger}{ }^{\dagger}$ Konstantinos D. Demadis, ${ }^{*},{ }^{\circledR}$ and Pascual Olivera-Pastor ${ }^{*}{ }^{\dagger}$

†Departamento de Química Inorgánica, Universidad de Málaga, Campus Teatinos s/n, Málaga 29071, Spain

${ }^{\ddagger}$ Faculty of Science \& Engineering, University of Wolverhampton, Wulfruna Street, Wolverhamton WV1 1LY, U.K.

${ }^{\S}$ Crystal Engineering, Growth and Design Laboratory, Department of Chemistry, University of Crete, Voutes Campus, Heraklion, Crete GR-71003, Greece

"Institut für Anorganische Chemie, Christian-Albrechts-Universität zu Kiel, 24098 Kiel, Germany

${ }^{\perp}$ Laboratoire de Chimie Moléculaire et Thioorganique, ENSICAEN \& Université de Caen, UMR CNRS 6507, INC3M, FR 3038 Caen, France

\#Instituto de Ciencia y Tecnología de Polímeros (ICTP-CSIC), Juan de la Cierva 3, 28006 Madrid, Spain

Supporting Information

ABSTRACT: Metal phosphonates containing acidic groups exhibit a wide range of proton conduction properties, which may enhance the performance of membrane electrode assemblies (MEAs). In this work, focus is placed on proton conduction properties of coordination polymers derived from the combination of lanthanide ions with a phosphonate derivative of taurine (2-[bis(phosphonomethyl)amino]ethanesulfonic acid, $\left.\mathbf{H}_{5} \mathbf{S P}\right)$. High-throughput hydrothermal screening $\left(140{ }^{\circ} \mathrm{C}\right)$ was used to reach optimal synthesis conditions and access pure crystalline phases. Seven compounds with the composition $\operatorname{Ln}\left[\mathbf{H}\left(\mathrm{O}_{3} \mathbf{P C H}_{2}\right)_{2}-\mathrm{NH}-\right.$ $\left.\left(\mathrm{CH}_{2}\right)_{2}-\mathrm{SO}_{3}\right] \cdot 2 \mathrm{H}_{2} \mathrm{O}$ were isolated and characterized, which

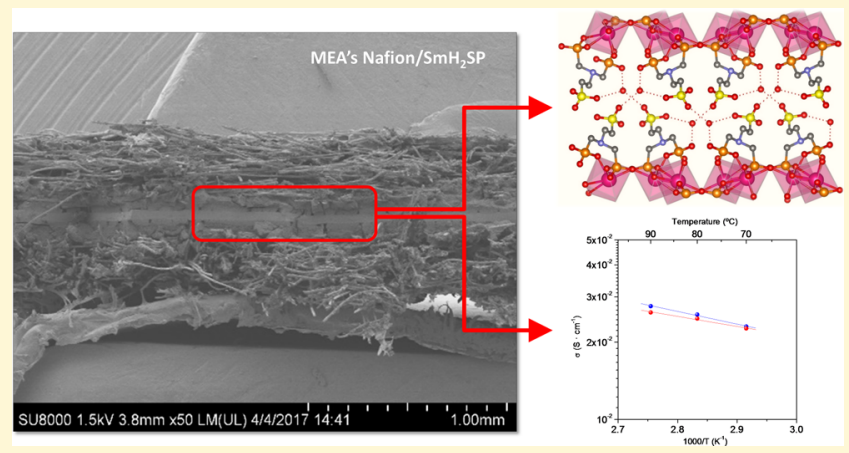
crystallize in two different structures, monoclinic $m$ - $\mathrm{LaH}_{2} \mathrm{SP}$ and orthorhombic $\boldsymbol{o}$ - $\mathrm{LnH}_{2} \mathrm{SP}\left(\mathbf{L n}=\mathbf{P r}, \mathbf{N d}, \mathbf{S m}, \mathbf{E u}, \mathbf{G d}\right.$, and Tb), with unit cell volumes of $\sim 1200$ and $\sim 2500 \AA^{3}$, respectively. Their crystal structures, solved $\mathrm{ab}$ initio from X-ray powder diffraction data, correspond to different layered frameworks depending on the $\mathrm{Ln}^{3+}$ cation size. In the orthorhombic series, $\boldsymbol{o}-\mathrm{LnH}_{2} \mathrm{SP}$, the sulfonate group is noncoordinated and points toward the interlayer space, while for $m-\mathrm{LaH}_{2} \mathrm{SP}$, both phosphonate and sulfonate groups coordinate to the $\mathrm{Ln}^{3+}$ centers. As a consequence, different $\mathrm{H}$-bonding networks and proton transfer pathways are generated. Proton conductivity measurements have been carried out between 25 and $80{ }^{\circ} \mathrm{C}$ at $70-95 \%$ relative humidity. The $\mathrm{Sm}^{3+}$ derivative exhibits a conductivity of $\sim 1 \times$ $10^{-3} \mathrm{~S} \cdot \mathrm{cm}^{-1}$ and activation energy characteristic of a Grotthuss-type mechanism for proton transfer. Preliminary MEA assays indicate that these layered lanthanide sulfophosphonates assist in maintaining the proton conductivity of Nafion membranes at least up to $90{ }^{\circ} \mathrm{C}$ and perform satisfactorily in single proton-exchange membrane fuel cells.

\section{INTRODUCTION}

Recent interest in phosphonate-based coordination polymers (CPs) relies on chemical robustness and functional versatility of metal phosphonate materials, which make them attractive for a number of potential applications. ${ }^{1-5}$ Among the CPbased proton conductors, metal phosphonates hold a prominent position. $^{6-8}$ Such materials are sought due to their attractive properties such as: (a) hydrolytic stability of the $\mathrm{P}-\mathrm{C}$ and $\mathrm{M}-\mathrm{O}$ bonds, ${ }^{9,10}$ (b) stability to higher temperatures, ${ }^{11}$ (c) structures with well-defined proton conduction pathways, ${ }^{12-17}$ (d) acidic sites on the ligands, ${ }^{18-22}$ or (e) presence of lattice water molecules that commonly participate in the proton conduction mechanism. ${ }^{23-26}$ Efforts have been put forth to enhance the proton conduction efficiency by introducing acidic moieties into the phosphonate ligand backbone $\mathrm{e}^{27,28}$ or by replacing the phosphonate ligand altogether with another that possesses (more) acidic groups. ${ }^{29,30}$ One prominent example is the sulfonate group. Metal phosphonates containing sulfonate groups have been among the first such materials that were studied for proton

Received: July 19, 2019

Revised: November 6, 2019

Published: November 7, 2019 
conductivity. ${ }^{31}$ These early efforts have been concisely reviewed in the literature. ${ }^{6}$ The presence of acidic (hydrogenphosphonate and/or sulfonic) groups interacting with water molecules in the crystal structure may define proton conduction pathways. ${ }^{32}$ There are some recent examples of sulfonate-containing metal phosphonates. For their preparation, both flexible $\mathrm{e}^{33,34}$ and rigid $^{35,36}$ phosphonosulfonate ligands have been employed.

Up to now, mainly tetravalent metal sulfophosphonates have been investigated as proton conductors. For instance, Jang et al. reported a cerium(IV) sulfophenylphosphonate where the layer structure was post-synthetically sulfonated using $30 \%$ fuming $\mathrm{H}_{2} \mathrm{SO}_{4}$, producing a material with the formula $\mathrm{Ce}\left(\mathrm{O}_{3} \mathrm{PC}_{6} \mathrm{H}_{4} \mathrm{SO}_{3} \mathrm{H}\right)_{2} \cdot{ }^{37}$ Proton conduction was observed to be humidity-dependent and increased by one order of magnitude between 40 and $100 \%$ relative humitidy ( $\mathrm{RH})$. At $100 \% \mathrm{RH}$ and $100{ }^{\circ} \mathrm{C}$, conductivity values in excess of $10^{-2} \mathrm{~S}$. $\mathrm{cm}^{-1}$ were obtained. On the other hand, Zima et al. reported $\mathrm{Zr} p$-sulfophenylphosphonates with the formula $\mathrm{Zr}$ $\left(\mathrm{HO}_{3} \mathrm{SC}_{6} \mathrm{H}_{4} \mathrm{PO}_{3}\right)_{2} \cdot 2 \mathrm{H}_{2} \mathrm{O} .{ }^{38}$ However, the proton conductivity properties of this solid were worse than those of the mixed $\mathrm{Zr}$ phosphate/sulfophenylphosphonate derivative (conductivity values from 0.028 to $0.063 \mathrm{~S} \cdot \mathrm{cm}^{-1}$ in the $\mathrm{RH}$ range of $50-$ $90 \%)$.

Incorporating inorganic nanoparticles is a well-established strategy to improve properties of polymer electrolyte membranes (PEMs), with effects such as increased working temperature, reduced swelling, enhanced water management and mechanical properties, etc. For this purpose, getting homogeneously dispersed inorganic fillers inside the polymeric matrix is highly desirable. ${ }^{39}$ Recently, metal sulfophosphonates have been combined with Nafion to produce composite membranes. For example, 6.5 and $12.5 \mathrm{wt} \%$ zirconium sulphophenyl phosphate-loaded composites have been reported to improve proton conductivity from $90{ }^{\circ} \mathrm{C}$ upward with respect to the unmodified Nafion. ${ }^{40}$

In this paper, we report the synthesis and structural characterization of two lanthanide framework structures of composition $\mathrm{Ln}\left[\mathrm{H}\left(\mathrm{O}_{3} \mathrm{PCH}_{2}\right)_{2}-\mathrm{NH}-\left(\mathrm{CH}_{2}\right)_{2}-\mathrm{SO}_{3}\right] \cdot 2 \mathrm{H}_{2} \mathrm{O}$ containing the ligand 2-[bis(phosphonomethyl)amino]ethanesulfonic acid $\left(\mathbf{H}_{5} \mathbf{S P}\right) . \mathbf{H}_{5} \mathbf{S P}$ is a phosphonomethylated derivative of taurine (2-aminoethanesulfonic acid). The proton conductivity properties of the $m-\mathrm{LaH}_{2} \mathrm{SP}$ and $o-\mathrm{LnH}_{2} \mathrm{SP}(\mathbf{L n}=$ Pr, Nd, Sm, Eu, Gd, and $\mathbf{T b}$ ) coordination polymers, as representative compounds, are reported. Lastly, it is highlighted that the structural role and orientation of the sulfonic group of the SP ligand contribute to tune the H-bonding network and, hence, the proton transfer processes.

\section{EXPERIMENTAL SECTION}

Reagents and Materials. Hydrated lanthanide nitrates [M$\left(\mathrm{NO}_{3}\right)_{3} \cdot 6 \mathrm{H}_{2} \mathrm{O}, \mathrm{M}^{3+}=\mathrm{La}, \mathrm{Ce}, \mathrm{Pr}, \mathrm{Nd}, \mathrm{Sm}$, and $\left.\mathrm{Gd}\right]$ or chlorides $\left(\mathrm{MCl}_{3} \cdot 6 \mathrm{H}_{2} \mathrm{O}, \mathrm{M}^{3+}=\mathrm{Eu}\right.$ and $\left.\mathrm{Tb}\right)$ were purchased from Sigma-Aldrich and used as received without further purification. Nafion $1100 \mathrm{EW}$ dispersion $20 \mathrm{wt} \%$ in a mixture of water and alcohols was purchased from Ion Power. Isopropanol was obtained from Merck \& Co. Inhouse, deionized (DI) water was used for all syntheses. Taurine (AlfaAesar, w/w 99\%), phosphorous acid (Alfa-Aesar, w/w 98\%), formaldehyde $(36.5 \% \mathrm{w} / \mathrm{w}$ aqueous solution, Scharlab S.L.), and organic solvents (acetone, diethyl ether, and ethanol) were purchased from various commercial sources and were used as received. Stock solutions of $\mathrm{HCl}(0.5 \mathrm{M}), \mathrm{HNO}_{3}(0.2$ and $0.5 \mathrm{M})$, and $\mathrm{NaOH}(0.2$ and $0.5 \mathrm{M})$ were used for $\mathrm{pH}$ adjustments.
Synthesis of [Bis(phosphonomethyl)amino]-ethanesulfonate Salts. The synthesis of the ligand $\mathbf{H}_{5} \mathbf{S P}$ was first reported in the patent literature. ${ }^{41}$ Due to scarce details and lack of characterization data, the synthesis of $\mathbf{H}_{5} \mathbf{S P}$ was explored more systematically herein. The tris-ammonium or pentasodium salts of this ligand were synthesized by following the Irani-Moedritzer reaction. ${ }^{42}$ Taurine (3.129 g, $0.025 \mathrm{~mol})$, phosphorous acid $(4.100 \mathrm{~g}, 0.050 \mathrm{~mol})$, DI water $(40 \mathrm{~mL})$, concentrated hydrochloric acid $(37 \%, 10 \mathrm{~mL})$, and a magnetic stir bar were introduced into a $250 \mathrm{~mL}$ two-necked round bottom flask. It was placed in an oil bath, charged with a condenser and a dropping funnel containing formaldehyde $(8 \mathrm{~mL})$, and the mixture was heated for $1 \mathrm{~h}$ maintaining a steady reflux. Subsequently, the formaldehyde solution was added dropwise into the boiling mixture during $\sim 1 \mathrm{~h}$ and reflux was maintained for $\sim 20 \mathrm{~h}$. The resulting mixture (with a deep orange-red color) was cooled down to room temperature under stirring. The reaction mixture was then poured into a glass beaker $(500 \mathrm{~mL})$ and $100 \mathrm{~mL}$ of acetone was added under stirring. The resulting mixture was heated and stirred again until the volume reaches $\sim 50 \mathrm{~mL}$ and finally left to cool down to room temperature. Its volume was further reduced using a rotary evaporator down to a volume of $\sim 25 \mathrm{~mL}$ and anhydrous ethanol (10 $\mathrm{mL}$ ) was added. A homogenous mixture resulted after rigorous stirring. Diethyl ether $(30 \mathrm{~mL})$ was then added under stirring, resulting in the formation of two phases. The aqueous phase (orange) was collected, while the organic phase was discarded. The process was repeated one more time. After successive treatments with organic solvents (ethanol, acetone, and diethyl ether), a viscous phase was obtained and was dissolved in water $(15-20 \mathrm{~mL})$. Solid $\mathrm{NaOH}$ was added to it until $\mathrm{pH}$ reached a value of $\sim 10$. Then, anhydrous ethanol $(20 \mathrm{~mL})$ was added to the mixture, which resulted in the formation of two phases. The bottom one (slight yellow-orange) contains the desired product and was carefully collected, while the top one contains all the side products and was discarded. The bottom layer was taken to dryness by boiling off the solvents. The resulting solid was then heated for $20 \mathrm{~min}$ in an oven at a temperature not exceeding $120{ }^{\circ} \mathrm{C}$ to avoid thermal decomposition. The pure hygroscopic product was immediately placed in a vial tightly closed and was kept in a desiccator. Yield: $3.9 \mathrm{~g}(37 \%)$. Elemental analysis (weight \%) for $\mathrm{Na}_{5}\left[\left(\mathrm{O}_{3} \mathrm{PCH}_{2}\right)_{2}-\mathrm{N}-\mathrm{CH}_{2} \mathrm{CH}_{2} \mathrm{SO}_{3}\right] \cdot 4 \mathrm{H}_{2} \mathrm{O}, \mathrm{Na}_{5} \mathrm{SP}(\mathrm{MW}=494.93 \mathrm{~g} /$ mol), Calcd: C 9.70, H 3.29, N 2.83, S 6.46. Found: C 10.16, H 4.09, $\mathrm{N} 3.06$, S 6.55; NMR data can be found in the Supporting Information.

The $\left(\mathrm{NH}_{4}\right)_{3} \mathbf{H}_{2} \mathbf{S P}$ analogue was isolated as follows: A quantity of the SP acid viscous liquid was dissolved in $50 \mathrm{~mL}$ of a $28 \%$ ammonia solution. Addition of $80 \mathrm{~mL}$ of ethanol resulted in a phase separation. The bottom phase was collected and was then gently heated to dryness giving a white solid. The solid was then collected and heated in the oven at $120{ }^{\circ} \mathrm{C}$ for half hour. Elemental analysis for $\left(\mathrm{NH}_{4}\right)_{3}\left[\mathrm{H}_{2}\left(\mathrm{O}_{3} \mathrm{PCH}_{2}\right)_{2}-\mathrm{NH}-\mathrm{CH}_{2} \mathrm{CH}_{2} \mathrm{SO}_{3}\right] \cdot 2 \mathrm{H}_{2} \mathrm{O},\left(\mathrm{NH}_{4}\right)_{3} \mathrm{H}_{2} \mathrm{SP}$ $(\mathrm{MW}=400.28 \mathrm{~g} / \mathrm{mol})$, Calcd (wt \%): C 12.0, H 6.55, N 14.00, S 8.01. Found: C 12.56, H 6.13, N 14.07, S 7.54.

Synthesis of $\operatorname{Ln}\left[\mathrm{H}_{(}\left(\mathrm{O}_{3} \mathrm{PCH}_{2}\right)_{2}-\mathrm{NH}-\left(\mathrm{CH}_{2}\right)_{2}-\mathrm{SO}_{3}\right] \cdot 2 \mathrm{H}_{2} \mathrm{O}$ $\mathrm{LnH}_{2} \mathrm{SP},\left(\mathrm{Ln}^{\mathrm{III}}=\mathrm{La}, \mathrm{Pr}, \mathrm{Nd}, \mathrm{Sm}, \mathrm{Eu}, \mathrm{Gd}\right.$, and Tb). The chemical system was systematically investigated using high-throughput methods to optimize reaction parameters. The optimal conditions were used for the scale up and are the following. As an example, for $\boldsymbol{m}$ $\mathrm{LaH}_{2} \mathrm{SP}, 0.0346 \mathrm{~g}(0.0799 \mathrm{mmol})$ of $\mathrm{La}\left(\mathrm{NO}_{3}\right)_{3} \cdot 6 \mathrm{H}_{2} \mathrm{O}$ was dissolved in $0.5 \mathrm{~mL}$ of DI water. In a separated glass container, $0.050 \mathrm{~g}(0.1597$ $\mathrm{mmol})$ of $\left(\mathrm{NH}_{4}\right)_{3} \mathrm{H}_{2} \mathrm{SP}$ was dissolved in $0.5 \mathrm{~mL}$ of DI water. The $\mathrm{La}^{3+}$ solution was added dropwise to the ligand solution under vigorous stirring at room temperature. The resulting slurry was redissolved by adding $\mathrm{HNO}_{3}$ stock solution to a final $\mathrm{pH}$ of 1.2. This solution was then transferred to a $5 \mathrm{~mL}$ Teflon-lined autoclave and heated at 140 ${ }^{\circ} \mathrm{C}$ for $24 \mathrm{~h}$ after which it was cooled to room temperature for $12 \mathrm{~h}$. The obtained precipitate was filtered off, washed twice with DI water and $\mathrm{EtOH}$, and, finally, dried at room temperature. $\boldsymbol{o}-\mathrm{GdH}_{2} \mathrm{SP}$ and $\boldsymbol{o}$ $\mathrm{TbH}_{2} \mathrm{SP}$ were prepared from $\mathrm{Na}_{5} \mathrm{SP}$, following the same procedure.

The $\boldsymbol{o}-\mathrm{EuH}_{2} \mathrm{SP}$ compound was prepared by a microwave-assisted synthesis as follows: $0.150 \mathrm{~g}(0.3087 \mathrm{mmol})$ of $\mathrm{Na}_{5} \mathrm{SP}$ was dissolved in $1.5 \mathrm{~mL}$ of DI water. In a separate glass tube, $0.057 \mathrm{~g}(0.1543$ 
Table 1. Crystallographic Data and Rietveld Disagreement Factors for $\mathrm{Ln}\left[\mathrm{H}\left(\mathrm{O}_{3} \mathrm{PCH}_{2}\right)_{2}-\mathrm{NH}-\left(\mathrm{CH}_{2}\right)_{2}-\mathrm{SO}_{3}\right] \cdot 2 \mathrm{H}_{2} \mathrm{O}\left(\mathrm{LnH}_{2} \mathrm{SP}\right.$, Ln = La, Pr, Nd, Sm, Eu, Gd, and Tb)

\begin{tabular}{|c|c|c|c|c|c|c|c|}
\hline parameter & $m-\mathrm{LaH}_{2} \mathrm{SP}$ & $o-\mathrm{PrH}_{2} \mathrm{SP}$ & $o-\mathrm{NdH}_{2} \mathrm{SP}$ & $o-\mathrm{SmH}_{2} \mathrm{SP}$ & $o$ - $\mathrm{EuH}_{2} \mathrm{SP}$ & $o-\mathrm{GdH}_{2} \mathrm{SP}$ & $o-\mathrm{TbH}_{2} \mathrm{SP}$ \\
\hline crystal system & monoclinic & orthorhombic & orthorhombic & orthorhombic & orthorhombic & orthorhombic & orthorhombic \\
\hline space group & $\mathrm{P} 2_{1} / c$ & $P c a b$ & $P c a b$ & $P c a b$ & $P c a b$ & $P c a b$ & $P c a b$ \\
\hline$\lambda(\AA)$ & 0.4124 & 0.4124 & 0.7093 & 0.4124 & 0.7093 & 0.7093 & 0.7093 \\
\hline$a(\AA)$ & $12.07146(21)$ & $12.9856(1)$ & $12.9311(3)$ & $12.8712(2)$ & $12.8176(5)$ & $12.7829(3)$ & $12.7519(6)$ \\
\hline$b(\AA)$ & $7.51420(13)$ & $27.9504(5)$ & $27.9525(10)$ & $28.0803(7)$ & $27.905(2)$ & $27.9622(8)$ & $27.9883(16)$ \\
\hline$c(\AA)$ & $14.27985(21)$ & $7.1552(1)$ & $7.1194(2)$ & $7.0675(1)$ & $7.0599(2)$ & $7.0407(2)$ & $7.0192(3)$ \\
\hline$\alpha\left(^{\circ}\right)$ & 90.00 & 90.00 & 90.00 & 90.00 & 90.00 & 90.00 & 90.00 \\
\hline$\beta\left(^{\circ}\right)$ & $103.0966(12)$ & 90.00 & 90.00 & 90.00 & 90.00 & 90.00 & 90.00 \\
\hline$\gamma\left({ }^{\circ}\right)$ & 90.00 & 90.00 & 90.00 & 90.00 & 90.00 & 90.00 & 90.00 \\
\hline$V\left(\AA^{3}\right)$ & $1261.60(4)$ & $2597.01(7)$ & $2573.36(15)$ & $2554.41(10)$ & $2525.17(26)$ & $2516.59(13)$ & $2505.17(28)$ \\
\hline$Z$ & 4 & 8 & 8 & 8 & 8 & 8 & 8 \\
\hline range data $\left(^{\circ}\right)$ & $3.5-40.0$ & $1.2-40$ & $5.3-45$ & $1.2-40$ & $5.3-40$ & $5.3-45$ & $5.3-45$ \\
\hline independent reflections & 1509 & 7149 & 2092 & 1303 & 1661 & 2049 & 2041 \\
\hline data restraints/parameters & $6490 / 40 / 118$ & $6323 / 40 / 113$ & $4009 / 40 / 109$ & $6235 / 48 / 111$ & $3970 / 40 / 107$ & $4010 / 40 / 109$ & $4010 / 40 / 107$ \\
\hline$R_{\mathrm{wp}}$ & 0.0621 & 0.0361 & 0.0428 & 0.0617 & 0.0887 & 0.0452 & 0.0671 \\
\hline$R_{\mathrm{p}}$ & 0.0440 & 0.0242 & 0.0326 & 0.0410 & 0.0692 & 0.0340 & 0.0490 \\
\hline$R_{\mathrm{F}}$ & 0.0225 & 0.0089 & 0.0137 & 0.0242 & 0.0194 & 0.0137 & 0.0178 \\
\hline CCDC & 1922823 & 1922825 & 1922824 & 1922822 & 1936877 & 1922821 & 1922826 \\
\hline
\end{tabular}

$\mathrm{mmol}$ ) of $\mathrm{EuCl}_{3} \cdot 6 \mathrm{H}_{2} \mathrm{O}$ was dissolved in $1.5 \mathrm{~mL}$ of $\mathrm{DI}$ water. This solution was slowly added to the $\mathrm{Na}_{5} \mathrm{SP}$ ligand solution under vigorous stirring at room temperature. The $\mathrm{pH}$ of the mixture was adjusted to 1.2 by using $\mathrm{HCl}$ stock solutions and transferred to a 10 $\mathrm{mL}$ glass vial. An Anton Paar Monowave 300 microwave reactor was used to carry out the reaction fixing a temperature of $140{ }^{\circ} \mathrm{C}$ for 60 min and under constant magnetic stirring (1200 rpm). The obtained precipitate was recovered by centrifugation, washed with DI water and ethanol, and dried at room temperature.

Elemental analysis (weight \%) for $m$ - $\mathrm{LaH}_{2} \mathrm{SP}$, Calcd: C 9.91, H 2.91, N 2.89, S 6.61. Found: C 8.58, H 2.63, N 2.98, S 5.36, yield (based on the metal) 51.8\%; $\boldsymbol{o}-\mathrm{PrH}_{2}$ SP, Calcd: C 9.86, H 2.90, N 2.88, S 6.58. Found: C 9.64, H 2.89, N 3.11, S 6.64, yield $\sim 83.2 \%$; o$\mathrm{NdH}_{2}$ SP, Calcd: C 9.68, H 2.88, N 2.86, S 6.54. Found: C 9.43, H 2.92, N 3.08, S 6.38, yield $~ 90.1 \% ; \boldsymbol{o}-\mathrm{SmH}_{2} \mathrm{SP}$, Calcd: C 9.68, H 2.84, $\mathrm{N} 2.82$, S 6.46. Found: C 9.22, H 2.91, N 2.99, S 6.21, yield 63.3\%; o-Eu $\mathrm{H}_{2}$ SP, Calcd: C 10.01, H 2.52, N 2.92, S 6.68. Found: C 9.83, H

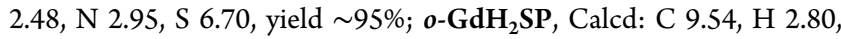
N 2.78, S 6.40. Found: C 9.41, H 2.84, N 2.81, S 6.19, yield 77.9\%; o- $\mathbf{T b H}_{2}$ SP, Calcd: C 9.51, H 2.79, N 2.77, S 6.35. Found: C 9.32, H 2.78, N 2.76, S 6.39, yield 79.6\%.

Chemical and Physical Characterization. Elemental analyses (C, N, H, and S) were performed with a Perkin-Elmer 240 analyzer. TGA traces of powder samples were recorded on an SDT-Q600 analyzer from TA Instruments. The temperature varied from RT to $900{ }^{\circ} \mathrm{C}$ with a heating rate of $10{ }^{\circ} \mathrm{C} \cdot \mathrm{min}^{-1}$. Measurements were carried out on samples in open platinum crucibles under a flow of air.

Structural Characterization. For structural determination of $m$ $\mathrm{LaH}_{2} \mathrm{SP}, o-\mathrm{PrH}_{2} \mathrm{SP}$, and $o-\mathrm{SmH}_{2} \mathrm{SP}$, synchrotron radiation X-ray powder diffraction (SR-XRDP) data were collected at the highresolution BL04-MSPD beamline of ALBA, the Spanish Synchrotron Radiation Facility (Barcelona, Spain). A wavelength of $0.4124 \AA$ was selected with a double-crystal $\mathrm{Si}(111)$ monochromator and determined from Si640d NIST standard $(a=5.43123 \AA)$ measurements. The capillary was rotated during data collection to improve diffracting particle statistics. The detector system was the MYTHEM, which allows fast collection of good resolution patterns over the angular range of $1.2-40^{\circ}(2 \theta)$. The crystal structures of $m-\mathrm{LaH}_{2} \mathrm{SP}$, $o$ - $\mathrm{PrH}_{2} \mathrm{SP}$, and $\boldsymbol{o}-\mathrm{SmH}_{2} \mathrm{SP}$ were solved following an ab initio methodology. The structure determinations were carried out by direct methods using the program EXPO2014. ${ }^{43}$ Partial structural models were obtained, and the missing atoms were localized by difference Fourier maps. All crystal structures were optimized by the Rietveld method ${ }^{44}$ using the program GSAS $^{45}$ and the graphic interface EXPGUI. ${ }^{46}$ The following soft constraints were imposed to preserve chemically reasonable geometries for the phosphonate, amine, alkyl chain, and sulfonic groups. The soft constrains were: $/ \mathrm{PO}_{3} \mathrm{C}$ tetrahedron $/ \mathrm{P}-\mathrm{O}(1.53(1) \AA), \mathrm{P}-\mathrm{C}(1.80(1) \AA ̊), \mathrm{O}-\mathrm{O}$ $(2.55(2) \AA), \mathrm{O}-\mathrm{C}(2.73(2) \AA) ; / \mathrm{N}\left(\mathrm{CH}_{2}\right)_{3}$ amine group $/ \mathrm{N}-\mathrm{C}$ $(1.50(1) \AA), \mathrm{C}-\mathrm{C}(2.45(2) \AA), \mathrm{N}-\mathrm{P}(2.68(2) \AA), \mathrm{N}-\mathrm{C}_{\text {chain }}(2.50(2)$ $\AA$ ), /alkyl chain/C-C (1.50(1) $\AA$ ), and $/ \mathrm{SO}_{3} \mathrm{C}$ tetrahedron $/ \mathrm{S}-\mathrm{O}$ (1.46(1) $\AA), S-C_{\text {chain }}(1.78(1) \AA), \mathrm{O}-\mathrm{O}(2.45(2) \AA)$, and $\mathrm{O}-\mathrm{C}$ $(2.58(2) \AA)$. No attempts to locate the $\mathrm{H}$ atoms were carried out due to the limited quality of the XRPD data.

For $o-\mathbf{L n H}_{2} \mathbf{S P}(\mathbf{L n}=\mathbf{N d}, \mathbf{G d}, \mathbf{E u}$, and $\mathbf{T b})$, X-ray powder diffraction data (XRDP) were collected on a D8 ADVANCE (Bruker AXS) diffractometer equipped with a Johansson $\mathrm{Ge}(111)$ primary monochromator, which gives a strictly monochromatic Mo radiation $(\lambda=0.7093 \AA)$. The X-ray tube was operating at $50 \mathrm{kV}$ and $50 \mathrm{~mA}$. The optics configuration was a fixed divergence slit $(2 \mathrm{~mm})$ and a fixed diffracted beam antiscatter slit $(9 \mathrm{~mm})$. The energy-dispersive linear detector LYNXEYE XE (500 mm) was used with the maximum opening angle. Under these conditions, the samples were measured between $2.8^{\circ}$ and $45^{\circ}(2 \theta)$, with a $0.01^{\circ}$ step size and an equivalent counting time of $\sim 2688 \mathrm{~s} / \mathrm{step}$. The samples were loaded in glass capillaries of $0.7 \mathrm{~mm}$ diameter and rotated during data collection to improve diffracting particle statistics. Their crystal structures were determined by the Rietveld method ${ }^{36}$ using the structure of $\boldsymbol{o}$ $\mathrm{SmH}_{2} \mathrm{SP}$ as a starting model and the soft constraints previously described to maintain chemically reasonable geometries. Crystal structures have been deposited with the CCDC, the reference codes and selected structural data are reported in Table 1, and the final Rietveld plots are given in the Supporting Information as Figures S1S7.

Thermal Stability. Thermodiffractometric studies for $m-\mathrm{LaH}_{2} \mathrm{SP}$ and $\boldsymbol{o}-\mathrm{SmH}_{2} \mathrm{SP}$ were carried out using an Anton Paar HTK1200N camera under static air. Data were collected at different temperatures up to $270{ }^{\circ} \mathrm{C}$ with a delay time of $15 \mathrm{~min}$ to ensure thermal equilibration. PXRD patterns were recorded between $4^{\circ}$ and $70^{\circ}$ in $2 \theta$, with a step size of $0.017^{\circ}$ and an equivalent counting time of $\sim 57$ s/step. In addition, crystallographic studies at different relative humidity values were collected on a D8 ADVANCE (Bruker AXS) diffractometer equipped with a Johansson $\mathrm{Ge}(111)$ primary monochromator, which gives a strictly monochromatic Mo radiation $(\lambda=0.7093 \AA)$ and an Anton Paar MHC-trans chamber. Data were collected between 30 and $80{ }^{\circ} \mathrm{C}$ and $95 \% \mathrm{RH}$ using a heating rate of 1 ${ }^{\circ} \mathrm{C} / \mathrm{min}$. Samples were measured between $2^{\circ}$ and $21^{\circ}(2 \theta)$ with a step size of $0.017^{\circ}$ and an equivalent counting time of $\sim 154$ s/step. Samples were held at each temperature for $10 \mathrm{~min}$ before recording any pattern, giving sufficient time for any transformation to take place. 
Particle Size Determination. The particle size measurements were carried out in a Zetasizer Nano ZS from Malvern. As a general procedure, the particle suspensions were prepared at a concentration of $\sim 1 \mathrm{mg} / \mathrm{mL}$ in MilliQ water and they were sonicated in a water bath for $1 \mathrm{~min}$ to get a homogeneous dispersion. The size was determined via dynamic light scattering (DLS) using a $632.8 \mathrm{~nm}$ wavelength laser as the light source. Then, the measurement was performed measuring backscattered light at $173^{\circ}$ to minimize multiple scattering, and the results were averaged and presented in intensity (raw data). The samples were measured in $1 \mathrm{~cm}$ path length disposable polystyrene cuvettes.

Proton Conductivity Studies. Impedance measurements of the powdered polycrystalline compounds were carried out on cylindrical pellets ( $\sim 5 \mathrm{~mm}$ diameter; $\sim 0.9-1.1 \mathrm{~mm}$ thickness) obtained by pressing $\sim 30-40 \mathrm{mg}$ of sample at $250 \mathrm{MPa}$ for $1 \mathrm{~min}$ between porous $\mathrm{C}$ electrodes (Sigracet, GDL $10 \mathrm{BB}$, no Pt). For $\boldsymbol{m}$ - $\mathrm{LaH}_{2} \mathrm{SP}$ and $\boldsymbol{o}$ $\mathrm{SmH}_{2} \mathrm{SP}$ compounds, the sample cells were placed inside a temperature and humidity-controlled chamber (Espec SH-222) and impedance data were collected using an HP4284A impedance analyzer over the frequency range from $20 \mathrm{~Hz}$ to $1 \mathrm{MHz}$ with an applied voltage of $1 \mathrm{~V}$. Both measurements were electronically controlled by the winDETA package of programs. ${ }^{47}$

To equilibrate the water content, pellets were first preheated $(0.2$ ${ }^{\circ} \mathrm{C} / \mathrm{min}$ ) from 25 to $80{ }^{\circ} \mathrm{C}$ at 70 and $95 \% \mathrm{RH}$. Impedance spectra were recorded on cooling using stabilization times of $3 \mathrm{~h}$ for each temperature $\left(80,70,60,50,40,30\right.$, and $\left.25^{\circ} \mathrm{C}\right)$. Water condensation on the sample was avoided by reducing first the relative humidity before decreasing temperature. The total pellet resistance $\left(R_{\mathrm{T}}\right)$ was obtained from the intercept of the spike and/or the arc (lowfrequency end) on the $Z^{\prime}$ axis from the Nyquist plots.

Preparation of Composite Membranes. Nafion $/ \mathrm{SmH}_{2} \mathrm{SP}-\mathrm{X}$ membranes $(\boldsymbol{X}=$ mass percentage $)$ containing $3 \%$ and $5 \%$ of $\boldsymbol{o}$ $\mathrm{SmH}_{2} \mathrm{SP}$ were prepared. As a representative example, the preparation process of the Nafion/ $\mathrm{SmH}_{2} \mathbf{S P}-3$ composite membrane is described in detail. Solid $\boldsymbol{o}$-SmH $\mathbf{S m}_{2} \mathbf{S P}(18 \mathrm{mg})$ was dispersed in 2-propanol (3 $\mathrm{mL})$ via magnetic stirring $(10 \mathrm{~min})$ and sonication $(10 \mathrm{~min})$ in three subsequent cycles. The suspension was slowly added to the $20 \mathrm{wt} \%$ Nafion solution $(3 \mathrm{~g})$ in a flask under magnetic stirring for $5 \mathrm{~min}$ and sonication at room temperature for $5 \mathrm{~min}$, in two subsequent cycles, producing a viscous homogeneous suspension. The membrane was prepared by casting using a blade (BYK Instruments) onto a polycarbonate plate that was allowed to air-dry for $48 \mathrm{~h}$. Finally, the obtained membrane (with a thickness of 35-40 $\mu \mathrm{m}$ ) was peeled off from the polycarbonate plate. Nafion and 5 wt $\% o-\mathbf{S m H}_{2}$ SP-loaded composite membranes were prepared using a similar procedure.

Membrane Characterization. All membranes were characterized by XRPD and thermal analysis under $\mathrm{N}_{2}$ and SEM (FEI, Helios Nanolab 650, and an energy-dispersive X-ray spectrometer, X-Max Oxford). Water uptake of Nafion, Nafion/ $\mathrm{SmH}_{2} \mathbf{S P}-3$, and Nafion/ $\mathrm{SmH}_{2}$ SP-5 were determined by measuring the weight variation before and after hydration. The samples were first dried under vacuum at 60 ${ }^{\circ} \mathrm{C}$ for $12 \mathrm{~h}$ and the weights were measured. Then, the samples were immersed in deionized water for $24 \mathrm{~h}$, wiped with a tissue paper to remove any excess water on the film surface, and rapidly weighed. The water uptake was calculated as a weight gain (wt \%) referred to the dried sample.

Electrochemical Characterization of the Membrane Electrode Assemblies (MEAs). For both anode and cathode, the catalyst layer ink consisted of Pt/C (40\% Pt on Vulcan XC-72, E-TEK) with a Pt load of $1 \mathrm{mg} \mathrm{Pt} \cdot \mathrm{cm}^{-2}, 30 \%$ Nafion (1100 EW), and 2:1 isopropanol/water mixture as dispersion media. After sonicating for 3 $\mathrm{h}$, the catalyst ink was sprayed onto a nonwoven carbon paper gas diffusion layer with a microporous layer (MPL) and 5\% PTFE treated (Sigracet 39 BC GDL) using an automatic spraying system EFD. An experimental $5 \mathrm{~cm}^{2}$ single cell (ElectroChem Inc.) was used as cell hardware for all the electrochemical measurements.

In Situ Through-Plane Proton Conductivity. Through-plane proton conductivity of the membranes has been determined on the MEAs at 70,80 , and $90{ }^{\circ} \mathrm{C}$ and $100 \% \mathrm{RH}$ by means of electrochemical impedance spectroscopy (EIS) using a potentiostat
Autolab PGStat30 equipped with an FRA module. The cell was continuously supplied $\left(200 \mathrm{~mL} \cdot \mathrm{min}^{-1}\right)$ with humidified hydrogen (SHE, anode) and nitrogen (cathode). The amplitude of the sinusoidal signal was $10 \mathrm{mV}$ and the frequency range was $100 \mathrm{kHz}$ to $10 \mathrm{~Hz}$. The spectra were recorded under a DC bias potential of $0.45 \mathrm{~V}$. The through-plane proton conductivity of the membranes $\sigma_{\mathrm{TP}}$ $\left(\mathrm{S} \cdot \mathrm{cm}^{-1}\right)$ was obtained using the following equation: $\sigma_{\mathrm{TP}}=L / R S$ where $L$ is the membrane thickness $(\mathrm{cm})$ and $S$ is the active area of the MEA $\left(5 \mathrm{~cm}^{2}\right)$.

The resistance $R(\Omega)$ was determined from Nyquist plots and it corresponds to the intercept with the real axis. Each sample was measured at least five times after it had reached a constant value to ensure good data reproducibility.

Performance Tests. Performance tests of the MEAs have been carried out using a Scribner 850e multirange fuel cell test system using hydrogen as fuel and oxygen as an oxidant $\left(200 \mathrm{~mL} \cdot \mathrm{min}^{-1}\right)$. The tests were run at atmospheric pressure, $80{ }^{\circ} \mathrm{C}$ cell temperature, and $100 \%$ relative humidity. The polarization curves were recorded after the single cell had reached stable conditions, that is, potential remained constant over time at a fixed current.

\section{RESULTS AND DISCUSSION}

Synthesis of Phosphonotaurine Ligand $\left(\mathrm{H}_{5} \mathrm{SP}\right)$. The synthesis of the ligand is conceptually easy and is achieved by following the well-established and repeatedly tested Mannichtype phosphonomethylation of amines (see Scheme 1, Supporting Information). ${ }^{48}$ The main challenge is isolation of $\mathbf{H}_{5} \mathrm{SP}$ in pure form and its full characterization, so the correct stoichiometry is used in the synthesis of the $\mathrm{Ln}$ derivatives. In our experience, tedious purification steps are necessary to yield pure and easily handled solid forms of the anion $\mathrm{SP}^{5-}$. The pure acid $\mathbf{H}_{5} \mathbf{S P}$ was never isolated. It is extremely hygroscopic (it invariably appears as a gummy solid) and absorbs water readily.

Two derivatives of $\mathbf{H}_{5} \mathbf{S P}$ were isolated and characterized. $\mathrm{Na}_{5} \mathrm{SP}$ was isolated by full deprotonation of the SP ligand and $\left(\mathrm{NH}_{4}\right)_{3} \mathbf{H}_{2} \mathbf{S P}$ by partial deprotonation (of the sulfonic and phosphonic moieties). Experimental conditions of $\mathbf{N a}_{5} \mathbf{S P}$ isolation gave rise to unavoidable marginal decomposition of the ligand as shown in the ${ }^{13} \mathrm{C}$ NMR spectrum (Figure S8).

Synthesis and Structural Characterization of $\mathrm{LnH}_{2} \mathrm{SP}$. Hydrothermal synthesis yielded compounds with the formula $\mathbf{L n}\left[\mathbf{H}\left(\mathrm{O}_{3} \mathbf{P C H}_{2}\right)_{2}-\mathbf{N H}-\left(\mathrm{CH}_{2}\right)_{2}-\mathrm{SO}_{3}\right] \cdot 2 \mathbf{H}_{2} \mathrm{O}$, with $\mathrm{Ln}=\mathbf{L a}$, Pr, Nd, Sm, Eu, Gd, and Tb. The $\mathrm{La}^{3+}$ derivative crystallizes in a distinct crystal structure while the other compounds form an isostructural series. The lower $\mathrm{C}$ and $\mathrm{S}$ percentages found for $m$ - $\mathrm{LaH}_{2} \mathrm{SP}$ can be interpreted as a consequence of the ligand fragmentation under the reaction conditions. This fragmentation of the ligand, to a small degree, occurs even during the ligand salt isolation and may extend further upon reaction with the lanthanide ions. As a result of the ligand fragmentation, an amorphous/semicrystalline fraction may accompany the crystalline phases $\left(\mathrm{La}^{3+}\right)$ or it occurs as a unique phase $\left(\mathrm{Ce}^{3+}\right)$. Other unidentified crystalline phases were obtained for $\mathrm{Er}^{3+}$ and $\mathrm{Yb}^{3+}$. No attempts to prepare other Ln compounds were made.

A monophasic $\mathrm{Eu}^{3+}$ derivative, $\boldsymbol{o}-\mathrm{EuH}_{2} \mathrm{SP}$, was obtained by applying a microwave-assisted synthesis methodology. This procedure can be a convenient synthetic method to further extend the preparation to other lanthanide derivatives, because it can considerably shorten the time of crystallization.

Thermogravimetric analysis of $\boldsymbol{m}$ - $\mathrm{LaH}_{2} \mathbf{S P}$ (Figure S9) shows a weight loss in three steps. The first weight loss stage, up to $\sim 190{ }^{\circ} \mathrm{C}$, corresponds to the loss of lattice water (found $3.75 \%$, calculated $3.71 \%$ ). The second stage, up to 250 
${ }^{\circ} \mathrm{C}$, is consistent with the loss of coordination water molecules (found $4.01 \%$, calculated $3.86 \%$ ). Further weight loss is associated with thermal decomposition of the ligand up to $850{ }^{\circ} \mathrm{C}$ (total experimental weight loss, 30.28\%). The thermodiffraction study for $\boldsymbol{m}-\mathrm{LaH}_{2} \mathbf{S P}$ (Figure S9) shows that the solid maintains its crystallinity at least up to $270{ }^{\circ} \mathrm{C}$ and reversibly rehydrates upon exposure at $98 \% \mathrm{RH}$, indicating that the layer structure is preserved in this process of dehydration/rehydration.

Thermogravimetric analyses of $\boldsymbol{o}-\mathbf{L n H}_{2} \mathrm{SP}$ compounds (Figure S10) show that the solids fully dehydrate at 100$150{ }^{\circ} \mathrm{C}$ (found $\sim 7.12-7.51 \%$, calculated $7.13-7.39 \%$ ) and start to decompose at $\sim 350{ }^{\circ} \mathrm{C}$. The final decomposition products at $900{ }^{\circ} \mathrm{C}$ (weight loss of $32-35.9 \%$ ) correspond to $\mathrm{LnPO}_{4}$. The thermodiffraction study of the sample $\boldsymbol{o}-\mathrm{SmH}_{2} \mathrm{SP}$ (Figure S10) indicates that the framework of the solid is stable at least up to $180{ }^{\circ} \mathrm{C}$ and that the solid retrieves all water upon rehydration, albeit with partial loss of crystallinity.

$m$ - $\mathrm{LaH}_{2} \mathrm{SP}$ crystallizes in the monoclinic crystal system in the space group $P 2_{1} / c$. The stoichiometry of the compound imposes the ligand to be triply deprotonated, one of the $\mathrm{H}^{+}$ ions being localized on the amine group. The asymmetric unit consists of one $\mathrm{La}^{3+}$ ion, one ligand, and two water molecules (one in the lattice, and one metal-coordinated). The coordination environment of $\mathrm{La}^{3+}$ is composed of four oxygen atoms from four phosphonate groups of ligands, three oxygen atoms from three sulfonate groups, and one oxygen atom from a water molecule (Figure 1). The layers in $\mathbf{m}-\mathbf{L a H}_{2} \mathbf{S P}$ are built

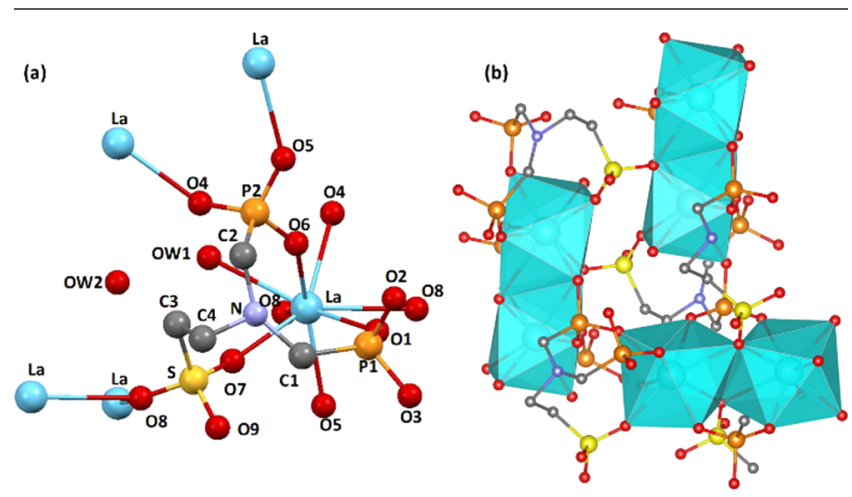

Figure 1. (a) View of $\mathrm{La}^{3+}$ coordination environment and (b) detail of the dimeric units in the layers of $m-\mathrm{LaH}_{2} \mathrm{SP}$.

up from edge-sharing dimers of $\mathrm{LnO}_{8}$ polyhedra interconnected by phosphonate and sulfonate groups. In this structure, the sulfonate groups bridge three metal centers by two oxygen atoms.

Two oxygen atoms, belonging to one of two crystallographically independent phosphonate groups (O2 and O3) and another one of the sulfonate group (O9), remain uncoordinated and point toward the interlayer region, where an H-bond network is formed with the participation of lattice water as indicated in Figure 2 and Table S1 in which H-bonds are represented by donor-acceptor distances since $\mathrm{H}$ atoms could not be localized.

The isostructural series $\boldsymbol{o}-\mathbf{L n H}_{2} \mathbf{S P}$ crystallizes in the orthorhombic crystal system in the space group Pcab. Relevant structural details are discussed only for the $\mathrm{Sm}^{3+}$ derivative as a representative example. As in the case of $m-\mathrm{LaH}_{2} \mathrm{SP}$, phosphonate groups are crystallographically independent, a difference between them being that one oxygen atom (O3) of the phosphonate group around P1 is noncoordinating. In addition, the sulfonate group does not coordinate to a metal center. The coordination environment of $\mathrm{Sm}^{3+}$ is composed of seven oxygen atoms from five different phosphonate groups, two of them bound in a bidentate fashion, and one oxygen atom from a water molecule (Figure 3).

The layers are built up from edge-sharing $\mathrm{SmO}_{8}$ polyhedra forming chains interconnected through the phosphonate groups (Figure 4). This connectivity leaves the sulfonate as a "free", noncoordinating group, pointing toward the interlayer region. Direct coordination of sulfonate to lanthanides has been found in both rigid and flexible lanthanide sulfophosphonates. $^{49-52}$ However, the rigid ligands display a preference of coordination through the phosphonate groups, ${ }^{52}$ except for $\mathrm{La}^{3+}$, which may be attributed to the larger size of the latter that makes possible simultaneous coordination with bulky groups. The free sulfonate groups in the interlamellar region contribute to create an $\mathrm{H}$-bonding network together with the lattice water molecule and the uncoordinated $\mathrm{P}-\mathrm{O}$ group (Figure 4). Moreover, the nonlocalized $\mathrm{H}^{+}$should also play an important role in this network.

Proton Conductivity. A study of the proton conductivity was undertaken to evaluate the effects of ligand connectivity to lanthanide ions and to address the issue of how available acidic groups contribute to proton transport in this kind of layered compound. The corresponding Nyquist plots for selected samples are shown in Figures S11 and S12. Post impedance Xray diffraction analyses indicated that the crystalline phases remain, although a partial amorphization takes place after impedance measurements (Figure S13). Proton conductivities of some derivatives, measured at $95 \% \mathrm{RH}$ and $80{ }^{\circ} \mathrm{C}$, are compared in Table 2.

$o-\mathrm{SmH}_{2} \mathrm{SP}$ displayed the highest proton conductivity value, which is within the range $\left(10^{-3}\right.$ to $\left.10^{-2} \mathrm{~S} \cdot \mathrm{cm}^{-1}\right)$ usually found for other phosphonate-based lanthanide coordination polymers such as PCMOF-5 ${ }^{6}$ (Table S3 and references herein).

The difference with respect to $\boldsymbol{m}$ - $\mathbf{L a H}_{2} \mathbf{S P}$ could be attributed in principle to the contribution of "free" sulfonate groups to proton transport by establishing more efficient proton transfer pathways (Figure 4 and Figure S14 and Table S2). However, the proton conductivity for the remaining $\boldsymbol{o}$ $\mathbf{L n H}_{2} \mathrm{SP}$ compounds is close to that of $m-\mathrm{LaH}_{2} \mathrm{SP}$, an indication that the measured total proton conductivity is a combination of various factors and not exclusively structural ones.

Morphologically, $\boldsymbol{o}$ - $\mathbf{L n H}_{2} \mathrm{SP}$ samples are composed of elongated platy particles reflecting the layer stacking (Figures S15-S17). The analysis of particle size distribution as measured by laser diffraction revealed broad bimodal distributions with two maxima around 250 and $1000 \mathrm{~nm}$ for the as-synthesized samples. However, post-impedance analyses of $\boldsymbol{o}-\mathrm{LnH}_{2} \mathrm{SP}$ series showed some significant changes in both particle size and morphology, despite that the TG curves did not reveal appreciable changes in weight loss (Figures S15$\mathrm{S} 17)$. While $\mathrm{Sm}^{3+}$ and $\mathrm{Nd}^{3+}$ samples hardly change in particle size, the $\mathrm{Eu}^{3+}$ sample experienced a remarkable decrease exhibiting a broader distribution centered around $300 \mathrm{~nm}$, indicative of considerable reduction in the number of larger size particles for this derivative. In general, the behavior observed appears to indicate that larger particle size favors higher conductivity, in accordance with a previous report by Wong et al., ${ }^{53}$ although subtle variations in $\mathrm{H}$-bond interactions (Figure S14) and morphology at measurement 


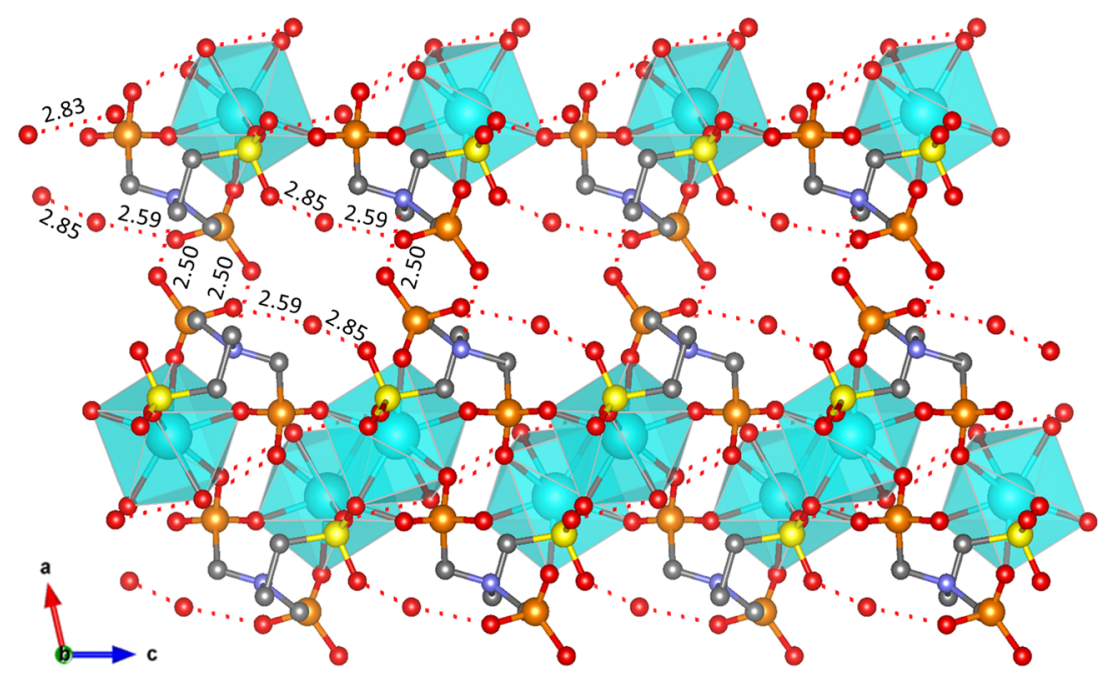

Figure 2. H-bonding network (donor-acceptor distances in $\AA$ ) within the interlayer region in the structure of $m$-LaH $\mathrm{LaH}_{2} \mathbf{S P}$.
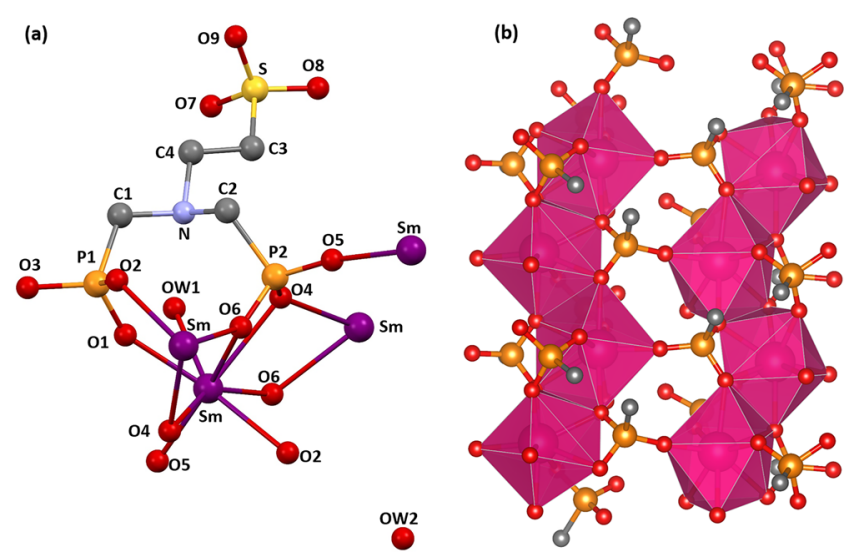

Figure 3. (a) View of $\mathrm{Sm}^{3+}$ coordination environment and (b) edgesharing $\mathrm{LnO}_{8}$ polyhedra chains for $\boldsymbol{o}-\mathrm{SmH}_{2} \mathrm{SP}$.

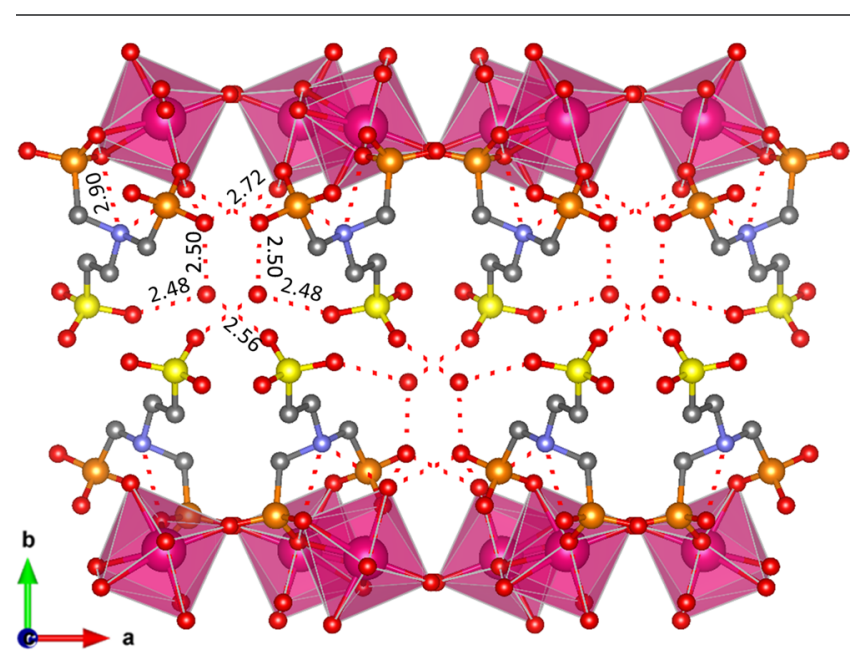

Figure 4. Packing of the layers for $\mathrm{o}-\mathrm{SmH}_{2} \mathrm{SP}$.

conditions also may contribute to the total proton conductivity. The activation energy values (Table 2) are in the range of those characteristics of a Grotthuss-type proton transfer mechanism. ${ }^{54,55}$

Membrane Characterization. The compound with the highest proton conductivity, $\boldsymbol{o}-\mathrm{SmH}_{2} \mathrm{SP}$, was selected for preparing composite membranes by using Nafion as the
Table 2. Proton Conductivity Values and Activation Energies for Selected $\mathrm{LnH}_{2} \mathrm{SP}$ Compounds

$\begin{array}{lcc}\text { compound } & \sigma\left(\mathrm{S} \cdot \mathrm{cm}^{-1}\right) & E_{\mathrm{a}}(\mathrm{eV}) \\ \boldsymbol{o}-\mathrm{NdH}_{2} \mathrm{SP} & 1.0 \times 10^{-4} & 0.49 \\ \boldsymbol{o}-\mathrm{SmH}_{2} \mathrm{SP} & 1.0 \times 10^{-3} & 0.3 \\ \boldsymbol{o}-\mathrm{EuH}_{2} \mathrm{SP} & 1.20 \times 10^{-4} & 0.50 \\ \boldsymbol{o}-\mathrm{TbH}_{2} \mathrm{SP} & 8.0 \times 10^{-5} & 0.4 \\ m-\mathrm{LaH}_{2} \mathrm{SP} & 1.20 \times 10^{-4} & 0.3\end{array}$

supporting polymeric matrix. As can be seen, the proton conductivity of both structural types increases by two orders of magnitude with the $\mathrm{RH}$ (Figure 5), but the $\mathrm{Sm}^{3+}$ derivative

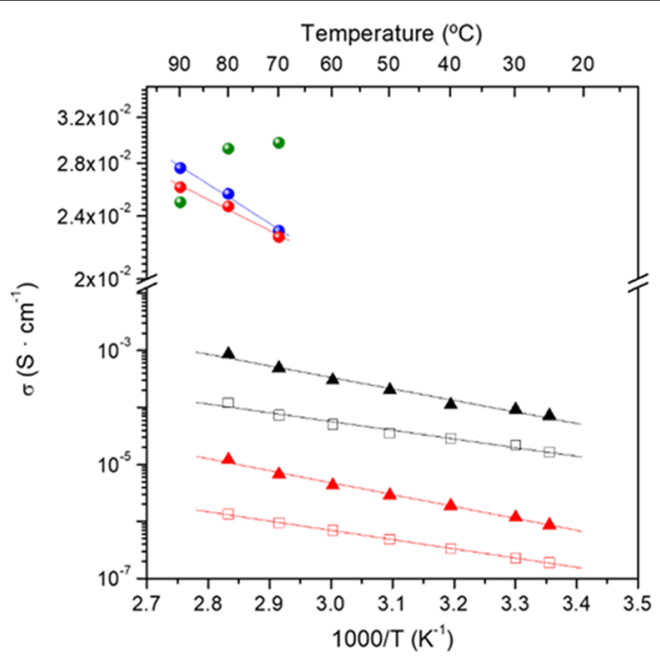

Figure 5. Arrhenius plots in the range $25-80{ }^{\circ} \mathrm{C}$ at $70 \% \mathrm{RH}$ (red) and $95 \% \mathrm{RH}$ (black) for $m$ - $\mathrm{LaH}_{2} \mathrm{SP}$ (square) and $\mathrm{o}-\mathrm{SmH}_{2} \mathrm{SP}$ (triangle) derivatives, unmodified Nafion membrane (green circles), Nafion/SmH2SP-3 (blue circles), and Nafion/SmH2SP-5 (red circles) composite membranes (100\% RH).

showed better performance in a wide range of $\mathrm{RH}$ values. XRPD patterns of composite membranes (Figure S18) display diffraction peaks characteristic of crystalline $\mathrm{o}-\mathrm{SmH}_{2} \mathrm{SP}$ together with a broad reflection, between $12^{\circ}$ and $20^{\circ}(2 \theta)$, corresponding to the $\mathrm{X}$-ray amorphous Nafion membrane. Water uptake measurements indicate a remarkable lower 


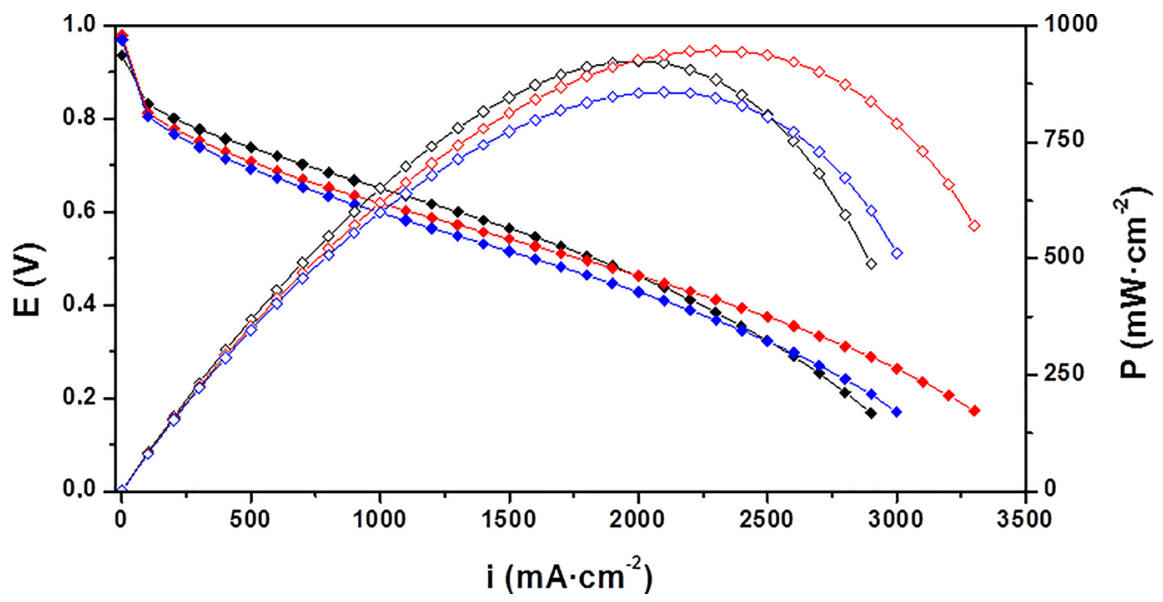

Figure 6. Polarization curves (full) and power density curves (open) of Nafion (black), Nafion/ $\mathrm{SmH}_{2} \mathrm{SP}-3$ (red), and Nafion/SmH 2 SP-5 (blue) composite membranes at $80{ }^{\circ} \mathrm{C}$ and $100 \% \mathrm{RH}$.

adsorption of water upon increasing $\mathrm{o}-\mathrm{SmH}_{2} \mathrm{SP}$ load, from $33.57 \%$ for Nafion to $25.4 \%$ for Nafion/ $\mathrm{SmH}_{2} \mathrm{SP}-3$ and $19.01 \%$ for Nafion/ $\mathrm{SmH}_{2} \mathrm{SP}-5$. SEM-EDS images of the Nafion/ $\mathrm{SmH}_{2} \mathrm{SP}-\boldsymbol{X}$ composite membranes (Figure S19) indicate a uniform distribution of submicrometric $\mathrm{o}-\mathrm{SmH}_{2} \mathrm{SP}$ particles inside the polymeric matrix together with larger particle aggregates, the latter are much more visible for the 5\%loaded sample. This may explain that the $3 \%$-loaded composite membrane exhibits higher water uptake.

The cross-sectional SEM images of the corresponding MEAs were obtained after ending the electrochemical tests (Figure S20). They show uniform 35-42 $\mu$ m-thick Nafion/ $\mathbf{S m H}_{2}$ SP-X and very good adhesion between layers indicating that the composite material is dimensionally stable under operating conditions and performance tests. In situ through-plane proton conductivity measurements show significant changes in the behavior of the composite membranes relative to the unmodified Nafion membrane (Figure 5). While the proton conductivity of Nafion decays in the range between 70 and 90 ${ }^{\circ} \mathrm{C}$, it increases with temperature and becomes higher in composite membranes at $90{ }^{\circ} \mathrm{C}$ and $100 \% \mathrm{RH}$ with values of $2.76 \times 10^{-2}$ and $2.61 \times 10^{-2} \mathrm{~S} \cdot \mathrm{cm}^{-1}$ for membranes with $\boldsymbol{o}$ $\mathrm{SmH}_{2}$ SP loadings of 3 and 5\%, respectively. This behavior can be attributed to widening the temperature range of optimal hydration in the composite membrane by the presence of hydrophilic particles of lanthanide phosphonate. Similar results were attained using Nafion-zirconium phosphate composite membranes functionalized with meta-sulphophenylphosphonic acid, $^{39}$ although high $\mathrm{Zr}$-phosphate loads $(20-40 \mathrm{wt} \%)$ were needed to make the composite membranes more conductive than pristine Nafion. The low activation energy values for $\boldsymbol{o}$ $\mathrm{SmH}_{2}$ SP-based composite membranes, $\sim 0.1 \mathrm{eV}$, are also remarkable and indicative of a highly facilitated proton transport through a Grotthuss-type mechanism.

As a preliminary study, the potential application of Nafion/ $\mathrm{SmH}_{2} \mathrm{SP}-\boldsymbol{X}$ proton exchange membranes in PEMFC was evaluated by cell performance analysis in $\mathrm{H}_{2} / \mathrm{O}_{2}$ single cells. Thus, the maximum current and power densities were determined at atmospheric pressure, $100 \% \mathrm{RH}$, and $80{ }^{\circ} \mathrm{C}$ cell temperature. Figure 6 shows the polarization and power density curves of Nafion/ $\mathbf{S m H}_{2} \mathbf{S P}-\boldsymbol{X}$ composites with 3 and 5 wt $\% o-\mathrm{SmH}_{2} \mathrm{SP}$ loadings and also of the pure Nafion membrane as a commercial reference material. The incorporation of $\mathrm{o}-\mathrm{SmH}_{2} \mathrm{SP}$ into the Nafion matrix leads to composite membranes that perform satisfactorily in PEMFC single cells. Specifically, the addition of 3 wt $\% o-\mathbf{S m H}_{2} \mathbf{S P}$ improves the electrochemical behavior of the Nafion membrane, reaching a maximum current density of $3300 \mathrm{~mA} \cdot \mathrm{cm}^{-2}$ and a maximum power density of $946 \mathrm{~m} \cdot \mathrm{Wcm}^{-2}$ while the corresponding values for pure Nafion are $2900 \mathrm{~mA} \cdot \mathrm{cm}^{-2}$ and $923 \mathrm{~mW} \cdot \mathrm{cm}^{-2}$, respectively. The best behavior of the composite Nafion/ $\mathrm{SmH}_{2} \mathrm{SP}-3$ could be related to the finer degree of dispersion in this case, as it was observed by SEM-EDS images. Besides this, the more uniform distribution of the filler also increases its specific surface area, which results in higher water retention capability compared to Nafion/ $\mathrm{SmH}_{2} \mathrm{SP}-5$, even when the amount of filler is lower. Thus, in light of these findings, the new composite membrane materials exhibit potential applicability as electrolytes in PEMFCs, although additional work would be necessary to improve the dispersion and homogeneity of the fillers.

\section{CONCLUSIONS}

A series of rare-earth sulfophosphonates of the composition $\mathrm{Ln}\left[\mathbf{H}\left(\mathrm{O}_{3} \mathrm{PCH}_{2}\right)_{2}-\mathrm{NH}-\left(\mathrm{CH}_{2}\right)_{2}-\mathrm{SO}_{3}\right] \cdot 2 \mathbf{H}_{2} \mathrm{O}$ were obtained via high-throughput and microwave-assisted methods. They were crystallized in two types of layered structures that differ in the coordination state of the sulfonate group. In the first structure type $\left(m-\mathrm{LaH}_{2} \mathrm{SP}\right)$, the sulfonate group is coordinated to the metal ion, whereas in the second $\left(o-\mathbf{L n H}_{2} \mathbf{S P}, \mathbf{L n}=\mathbf{P r}\right.$, Nd, Sm, Eu, Gd, and Tb), it is "free" and points to the interlayer space. These structural variations create different $\mathrm{H}$ bonding networks and proton transfer pathways in the two structure types. Impedance spectroscopy measurements indicate that these solids exhibit moderate/high proton conductivity values, $\sigma$ of $\sim 10^{-3} \mathrm{~S} \cdot \mathrm{cm}^{-1}\left(\boldsymbol{o}-\mathrm{SmH}_{2} \mathrm{SP}\right)$ at 80 ${ }^{\circ} \mathrm{C}$, and $95 \% \mathrm{RH}$. Preliminary studies on $\mathrm{Nafion} / \mathrm{SmH}_{2} \mathrm{SP}$ composite membranes suggest that doping Nafion with lanthanide sulfophosphonate CPs is a convenient way of maintaining high proton conductivity of Nafion at least up to $90{ }^{\circ} \mathrm{C}$, which makes these composite membranes attractive for PEMFCs.

\section{ASSOCIATED CONTENT}

\section{Supporting Information}

The Supporting Information is available free of charge at https://pubs.acs.org/doi/10.1021/acs.chemmater.9b02868. 
X-ray crystal details for $\boldsymbol{o}$ - $\mathbf{E u H}_{2} \mathrm{SP}$ (CIF)

X-ray crystal details for $\boldsymbol{o}-\mathbf{G d H}_{2} \mathbf{S P}$ (CIF)

$\mathrm{X}$-ray crystal details for $\boldsymbol{m}$ - $\mathrm{LaH}_{2} \mathrm{SP}$ (CIF)

$\mathrm{X}$-ray crystal details for $\boldsymbol{o}-\mathrm{NdH}_{2} \mathrm{SP}$ (CIF)

$\mathrm{X}$-ray crystal details for $\boldsymbol{o}$ - $\mathbf{P r H}_{2} \mathrm{SP}$ (CIF)

X-ray crystal details for $\boldsymbol{o}$ - $\mathbf{S m H}_{2} \mathrm{SP}$ (CIF)

$\mathrm{X}$-ray crystal details for $\boldsymbol{o}$ - $\mathbf{T} \mathbf{b} \mathbf{H}_{2} \mathbf{S P}$ (CIF)

Scheme 1; Figures S1-S7: Rietveld plots for $\mathbf{L n H}_{2} \mathbf{S P}$ compounds ( $\mathbf{L n}=\mathbf{L a}, \mathbf{P r}, \mathbf{N d}, \mathbf{S m}, \mathbf{E u}, \mathbf{G d}$, and $\mathbf{T b})$; Figure S8: ${ }^{13} \mathrm{C}$ NMR spectrum of $\mathrm{Na}_{5} \mathrm{SP}$; Figure S9: TGA curve and thermodiffractometric study for $m$ $\mathrm{LaH}_{2} \mathrm{SP}$; Figure S10: TGA curve and thermodiffractometric study for $o-\mathbf{L n H}_{2} \mathrm{SP}$; Figure S11: plots of the complex impedance plane for $\mathbf{L n H}_{2} \mathbf{S P}(\mathbf{L n}=\mathbf{L a}, \mathbf{N d}$, $\mathrm{Sm}, \mathbf{E u}$, and $\mathbf{T b}$ ) at 95\% RH; Figure S12: plots of the complex impedance plane for $\boldsymbol{m}$ - $\mathrm{LaH}_{2} \mathrm{SP}$ and $\boldsymbol{o}$ $\mathrm{SmH}_{2} \mathrm{SP}$ at $70 \% \mathrm{RH}$; Figure S13: XRPD patterns for $\boldsymbol{m}$ - $\mathrm{LaH}_{2} \mathrm{SP}$ and $\boldsymbol{o}-\mathrm{SmH}_{2} \mathrm{SP}$ as-synthesized and postimpedance, as representative compounds; Figure S14: significant $\mathrm{H}$-bond distances (donor-acceptor distances in $\AA$ ) in the interlayer region of $\boldsymbol{o}$ - $\mathbf{L n H}_{2} \mathrm{SP}$; Figure S15S17: SEM images, particle size distributions, and TG curves for $o-\mathbf{L n H}_{2} \mathrm{SP}(\mathrm{Ln}=\mathbf{N d}, \mathbf{S m}$, and $\mathbf{E u})$ before and post-impedance measurements; Figure S18: XRPD patterns of the as-synthesized $\boldsymbol{o}-\mathrm{SmH}_{2} \mathbf{S P}$ and composite membranes of Nafion/ $\mathrm{SmH}_{2} \mathrm{SP}$; Figure S19: SEM images showing $\mathrm{Sm}^{3+}$ EDS elemental mapping for Nafion/ $\mathrm{SmH}_{2} \mathrm{SP}$ composite membranes; Figure S20: SEM images of $\boldsymbol{o}-\mathrm{SmH}_{2} \mathrm{SP}$ polycrystalline sample and cross sections of MEA's Nafion/ $\mathbf{S m H}_{2} \mathbf{S P}-\boldsymbol{X}$; Table S1: summary of $\mathrm{H}$-bond interactions for $\boldsymbol{m}-\mathrm{LaH}_{2} \mathrm{SP}$; Table S2: summary of $\mathrm{H}$-bond interactions for $\mathrm{o}-\mathrm{SmH}_{2} \mathbf{S P}$; Table S3: proton conductivity values for selected lanthanide phosphonates (PDF)

\section{AUTHOR INFORMATION}

\section{Corresponding Authors}

*E-mail: demadis@uoc.gr (K.D.D.).

*E-mail: poliverap@uma.es (P.O.-P.).

\section{ORCID $\odot$}

Norbert Stock: 0000-0002-0339-7352

Enrique R. Losilla: 0000-0002-3361-2340

Aurelio Cabeza: 0000-0002-1582-3240

Konstantinos D. Demadis: 0000-0002-0937-8769

\section{Author Contributions}

This is part of the Ph.D. of Ms. Inés R. Salcedo. The manuscript was written through contributions of all authors. All authors have given approval to the final version of the manuscript.

\section{Funding}

The work at UMA was funded by MAT2016-77648-R research grant (Spain) and by Junta de Andalucia through the P12FQM-1656 research project. M.B.-G. thanks UMA Research Plan for financial support. The work at CSIC-Madrid was funded by PROTONCELL ENE2017-86711-C3-1-R and REPICOMES ENE2017-90932-REDT and MAT2016-81001P. The work at UoC was supported by grants from the Research Committee of the University of Crete, ELKE (grant no. KA 10329).

Notes

The authors declare no competing financial interest.

\section{ACKNOWLEDGMENTS}

Selected XRD experiments were performed at the BM04 beamline at ALBA Synchrotron (proposal no. 2016091873) with the collaboration of ALBA staff.

\section{REFERENCES}

(1) Bhanja, P.; Na, J.; Jing, T.; Lin, J.; Wakihara, T.; Bhaumik, A.; Yamauchi, Y. Nanoarchitectured metal phosphates and phosphonates: A new material horizon toward emerging applications. Chem. Mater. 2019, 31, 5343-5362.

(2) Shearan, S. J.; Stock, N.; Emmerling, F.; Demel, J.; Wright, P. A.; Demadis, K. D.; Vassaki, M.; Costantino, F.; Vivani, R.; Sallard, S.; Salcedo, I. R.; Cabeza, A.; Taddei. New directions in metal phosphonate and phosphinate chemistry. Crystals 2019, 9, 270.

(3) Firmino, A. D.; Figueira, F.; Tomé, J. P.; Paz, F. A. A.; Rocha, J. Metal-Organic Frameworks assembled from tetraphosphonic ligands and lanthanides. Coord. Chem. Rev. 2018, 355, 133-149.

(4) Zhu, Y. P.; Ma, T. Y.; Liu, Y. L.; Ren, T. Z.; Yuan, Z. Y. Metal phosphonate hybrid materials: From densely layered to hierarchically nanoporous structures. Inorg. Chem. Front. 2014, 1, 360-383.

(5) Zhang, R.; El-Refaei, S. M.; Russo, P. A.; Pinna, N. Metal phosphonate coordination networks and frameworks as precursors of electrocatalysts for the hydrogen and oxygen evolution reactions. J. Nanopart. Res. 2018, 20, 146.

(6) Bao, S.-S.; Shimizu, G. K.; Zheng, L.-M. Proton conductive metal phosphonate frameworks. Coord. Chem. Rev. 2019, 378, 577-594.

(7) Shimizu, G. K.; Taylor, J. M.; Dawson, K. W. Metal organophosphonate proton conductors. In Metal Phosphonate Chemistry: From Synthesis to Applications; Clearfield, A.; Demadis, K.D. Eds.; Royal Society of Chemistry: London, 2012; Chapter 15, pp. 493-524.

(8) Li, A. L.; Gao, Q.; Xu, J.; Bu, X. H. Proton-conductive metalorganic frameworks: Recent advances and perspectives. Coord. Chem. Rev. 2017, 344, 54-82.

(9) Demadis, K. D.; Ketsetzi, A. Degradation of phosphonate-based scale inhibitor additives in the presence of oxidizing biocides: "Collateral damages" in industrial water systems. Sep. Sci. Technol. 2007, 42, 1639-1649.

(10) Demadis, K. D. Chemistry of organophosphonate scale inhibitors. Part 4: Stability of amino-tris(methylenephosphonate) towards degradation by oxidizing biocides. Phosphorus, Sulfur Silicon 2006, 181, 167-176.

(11) Hoffmann, T.; Friedel, P.; Harnisch, C.; Häußler, L.; Pospiech, D. Investigation of thermal decomposition of phosphonic acids. J. Anal. Appl. Pyrolysis 2012, 96, 43-53.

(12) Taylor, J. M.; Mah, R. K.; Moudrakovski, I. L.; Ratcliffe, C. I.; Vaidhyanathan, R.; Shimizu, G. K. H. Facile proton conduction via ordered water molecules in a phosphonate metal-organic framework. J. Am. Chem. Soc. 2010, 132, 14055-14057.

(13) Colodrero, R. M.; Papathanasiou, K. E.; Stavgianoudaki, N.; Olivera-Pastor, P.; Losilla, E. R.; Aranda, M. A.; León Reina, L.; Sanz, J.; Sobrados, I.; Choquesillo-Lazarte, D.; García-Ruiz, J. M.; Atienza, P.; Rey, F.; Demadis, K. D.; Cabeza, A. Multifunctional luminescent and proton-conducting lanthanide carboxyphosphonate open-framework hybrids exhibiting crystalline-to-amorphous-to-crystalline transformations. Chem. Mater. 2012, 24, 3780-3792.

(14) Bazaga-García, M.; Colodrero, R. M. P.; Papadaki, M.; Garczarek, P.; Zoń, J.; Olivera-Pastor, P.; Losilla, E. R.; León-Reina, L.; Aranda, M. A. G.; Choquesillo-Lazarte, D.; Demadis, K. D.; Cabeza, A. Guest molecule-responsive functional calcium phosphonate frameworks for tuned proton conductivity. J. Am. Chem. Soc. 2014, 136, 5731-5739.

(15) Alberti, G.; Boccali, L.; Casciola, M.; Massinelli, L.; Montoneri, E. Protonic conductivity of layered zirconium phosphonates containing $-\mathrm{SO}_{3} \mathrm{H}$ groups. III. Preparation and characterization of $\gamma$-zirconium sulfoaryl phosphonates. Solid State Ionics 1996, 84, 97104. 
(16) Enakieva, Y. Y.; Sinelshchikova, A. A.; Grigoriev, M. S.; Chernyshev, V. V.; Kovalenko, K. A.; Stenina, I. A.; Yaroslavtsev, A. B.; Gorbunova, Y. G.; Tsivadze, A. Y. Highly proton-conductive zinc metal-organic framework based on nickel(II) porphyrinylphosphonate. Chem. - Eur. J. 2019, 25, 10552-10556.

(17) Pan, J.; Ma, Y.-J.; Han, S.-D.; Hu, J.-X.; Mu, Y.; Wang, G.-M. Construction of the lanthanide diphosphonates via a templatesynthesis strategy: Structures, proton conduction, and magnetic behavior. Cryst. Growth Des. 2019, 19, 3045-3051.

(18) Parangi, T. F.; Chudasama, U. V. Synthesis, characterization, and proton conduction behavior of thorium and cerium phosphonates. ACS Omega 2019, 4, 3716-3725.

(19) Salcedo, I. R.; Colodrero, R. M. P.; Bazaga-García, M.; Vasileiou, A.; Papadaki, M.; Olivera-Pastor, P.; Infantes-Molina, A.; Losilla, E. R.; Mezei, G.; Cabeza, A.; Demadis, K. D. From light to heavy alkali metal tetraphosphonates $(\mathrm{M}=\mathrm{Li}, \mathrm{Na}, \mathrm{K}, \mathrm{Rb}, \mathrm{Cs})$ : Cation size-induced structural diversity and water-facilitated proton conductivity. Cryst. Eng. Comm. 2018, 20, 7648-7658.

(20) Lim, D.-W.; Sadakiyo, M.; Kitagawa, H. Proton transfer in hydrogen-bonded degenerate systems of water and ammonia in metal-organic frameworks. Chem. Sci. 2019, 10, 16-33.

(21) Zhang, J.; Chen, L.; Gui, D.; Zhang, H.; Zhang, D.; Liu, W.; Huang, G.; Diwu, J.; Chai, Z.; Wang, S. An ingenious one-dimensional zirconium phosphonate with efficient strontium exchange capability and moderate proton conductivity. Dalton Trans. 2018, 47, 51615165.

(22) Wang, M.; Luo, H.-B.; Liu, S.-X.; Zou, Y.; Tian, Z.-F.; Li, L.; Liu, J.-L.; Ren, X.-M. Water assisted high proton conductance in a highly thermally stable and superior water-stable open-framework cobalt phosphate. Dalton Trans. 2016, 45, 19466-19472.

(23) Begum, S.; Wang, Z.; Donnadio, A.; Costantino, F.; Casciola, M.; Valiullin, R.; Chmelik, C.; Bertmer, M.; Kärger, J.; Haase, J.; Krautscheid, H. Water-mediated proton conduction in a robust triazolyl phosphonate metal-organic framework with hydrophilic nanochannels. Chem. - Eur. J. 2014, 20, 8862-8866.

(24) Colodrero, R. M.; Olivera-Pastor, P.; Losilla, E. R.; HernándezAlonso, D.; Aranda, M. A. G.; Leon-Reina, L.; Rius, J.; Demadis, K. D.; Moreau, B.; Villemin, D.; Palomino, M. High proton conductivity in a flexible, cross-linked, ultramicroporous magnesium tetraphosphonate hybrid framework. Inorg. Chem. 2012, 51, 7689-7698.

(25) Chen, W.; Wang, J.; Zhao, L.; Dai, W.; Li, Z.; Li, G. Enhancing proton conductivity of a highly water stable $3 \mathrm{D} \mathrm{Sr}(\mathrm{II})$ metal-organic framework by exposure to aqua-ammonia vapour. J. Alloys Compd. 2018, 750, 895-901.

(26) Homburg, T.; Tschense, C. B. L.; Wolkersdoerfer, K.; Reinsch, H.; Wark, M.; Többens, D.; Zander, S.; Senker, J.; Stock, N. Magnesium doped gallium phosphonates $\mathrm{Ga}_{1-\mathrm{x}} \mathrm{Mg}_{\mathrm{x}}\left[\mathrm{H}_{3+\mathrm{x}}\left(\mathrm{O}_{3} \mathrm{PCH}_{2}\right)_{3} \mathrm{~N}\right](\mathrm{x}=0,0.20)$ and the influence on proton conductivity. Z. Anorg. Allg. Chem. 2018, 644, 86-91.

(27) Donnadio, A.; Nocchetti, M.; Costantino, F.; Taddei, M.; Casciola, M.; da Silva Lisboa, F.; Vivani, R. A layered mixed zirconium phosphate/phosphonate with exposed carboxylic and phosphonic groups: X-ray powder structure and proton conductivity properties. Inorg. Chem. 2014, 53, 13220-13226.

(28) Alberti, G.; Casciola, M.; Costantino, U.; Peraio, A.; Montoneri, E. Protonic conductivity of layered zirconium phosphonates containing $-\mathrm{SO}_{3} \mathrm{H}$ groups. I. Preparation and characterization of a mixed zirconium phosphonate of composition $\mathrm{Zr}$ $\left(\mathrm{O}_{3} \mathrm{PR}\right)_{0.73}\left(\mathrm{O}_{3} \mathrm{PR}^{\prime}\right)_{1.27} \cdot \mathrm{nH}_{2} \mathrm{O}$, with $\mathrm{R}=-\mathrm{C}_{6} \mathrm{H}_{4}-\mathrm{SO}_{3} \mathrm{H}$ and $\mathrm{R}^{\prime}=$ $-\mathrm{CH}_{2}-\mathrm{OH}$. Solid State Ionics 1992, 50, 315-322.

(29) Kim, S.; Dawson, K. W.; Gelfand, B. S.; Taylor, J. M.; Shimizu, G. K. Enhancing proton conduction in a metal-organic framework by isomorphous ligand replacement. J. Am. Chem. Soc. 2013, 135, 963966.

(30) Beyer, O.; Homburg, T.; Albat, M.; Stock, N.; Lüning, U. Synthesis of phosphonosulfonic acid building blocks as linkers for coordination polymers. New J. Chem. 2017, 41, 8870-8876.
(31) Alberti, G.; Casciola, M. Layered metal ${ }^{\text {IV }}$ phosphonates, a large class of inorgano-organic proton conductors. Solid State Ionics 1997, 97, 177-186.

(32) Ramaswamy, P.; Wong, N. E.; Gelfand, B. S.; Shimizu, G. K. H. A water stable magnesium MOF that conducts protons over $10^{-2} \mathrm{~S}$. $\mathrm{cm}^{-1}$. J. Am. Chem. Soc. 2015, 137, 7640-7643.

(33) Zhang, G.; Fei, H. Missing metal-linker connectivities in a 3-D robust sulfonate-based metal-organic framework for enhanced proton conductivity. Chem. Commun. 2017, 53, 4156-4159.

(34) Sonnauer, A.; Näther, C.; Höppe, H. A.; Senker, J.; Stock, N. Systematic investigation of lanthanide phosphonatoethanesulfonate framework structures by high-throughput methods. $\mathrm{Ln}\left(\mathrm{O}_{3} \mathrm{P}-\mathrm{C}_{2} \mathrm{H}_{4}-\right.$ $\left.\mathrm{SO}_{3}\right)\left(\mathrm{H}_{2} \mathrm{O}\right)(\mathrm{Ln}=\mathrm{La}-\mathrm{Dy})$. Inorg. Chem. 2007, 46, 9968-9974.

(35) Wöhlbrandt, S.; Beyer, O.; Reinsch, H.; Ken Inge, A.; Svensson Grape, E.; Lüning, U.; Stock, N. Five new coordination polymers with a bifunctional phosphonate-sulfonate linker molecule. Z. Anorg. Allg. Chem. 2019, 645, 732-739.

(36) Du, Z.-Y.; Xu, H.-B.; Mao, J.-G. Rational design of OD, 1D, and 3D open frameworks based on tetranuclear lanthanide(III) sulfonatephosphonate clusters. Inorg. Chem. 2006, 45, 9780-9788.

(37) Jang, M.; Park, Y.; Yamazaki, Y. Preparation, characterization and proton conductivity of layered cerium sulfophenylphosphonate. Electrochemistry 2003, 71, 691-694.

(38) Zima, V.; Svoboda, J.; Melanova, K.; Benes, L.; Casciola, M.; Sganappa, M.; Brus, J.; Trchova, M. Synthesis and characterization of new zirconium 4-sulfophenylphosphonates. Solid State Ionics 2010, $181,705-713$.

(39) Casciola, M.; Capitani, D.; Donnadio, A.; Frittella, V.; Pica, M.; Sganappa, M. Preparation, proton conductivity and mechanical properties of Nafion 117-Zirconium phosphate sulphophenylphosphonate composite membranes. Fuel Cells 2009, 9, 381-386.

(40) Kim, Y.; Song, M.; Kim, K.; Park, S.; Min, S.; Rhee, H. Nafion/ ZrSPP composite membrane for high temperature operation of PEMFCs. Electrochim. Acta 2004, 50, 645-648.

(41) Bendiksen, B.; Persinski, L. J.; Schaper, R. J. Multifunctional Scale Inhibitors. U.S. Patent 5,087,376A, 1990.

(42) Moedritzer, K.; Irani, R. R. The direct synthesis of $\alpha$ aminomethylphosphonic acids. Mannich-type reactions with orthophosphorous acid. J. Org. Chem. 1966, 31, 1603-1607.

(43) Altomare, A.; Cuocci, C.; Giacovazzo, C.; Moliterni, A.; Rizzi, R.; Corriero, N.; Falcicchio, A. EXPO2013: A kit of tools for phasing crystal structures from powder data. J. Appl. Crystallogr. 2013, 46, 1231-1235.

(44) Rietveld, H. M. A profile refinement method for nuclear and magnetic structures. J. Appl. Crystallogr. 1969, 2, 65-71.

(45) Larson, A. C.; von Dreele, R. B. General structure analysis system (GSAS) Report No. LA-UR-2000, 86-748.

(46) Toby, B. H. EXPGUI, a graphical user interface for GSAS. J. Appl. Crystallogr. 2001, 34, 210-213.

(47) Novocontrol. winDETA; Novocontrol GmbH: Hundsangen, Germany, 1995.

(48) Agababyan, A. G.; Gevorgyan, G. A.; Mndzhoyan, O. L. Aminoacids as the amine component in the Mannich reaction. Russ. Chem. Rev. 1982, 51, 387-396.

(49) Sonnauer, A.; Näther, C.; Höppe, H. A.; Senker, J.; Stock, N. Systematic Investigation of lanthanide phosphonatoethanesulfonate framework structures by high-throughput methods, $\mathrm{Ln}\left(\mathrm{O}_{3}-\mathrm{P}-\mathrm{C}_{2} \mathrm{H}_{4^{-}}\right.$ $\left.\mathrm{SO}_{3}\right)\left(\mathrm{H}_{2} \mathrm{O}\right)(\mathrm{Ln}=\mathrm{La}-\mathrm{Dy})$. Inorg. Chem. 2007, 46, 9968-9974.

(50) Sonnauer, A.; Stock, N. High-throughput and microwave investigation of rare earth phosphonateoethanesulfonates- $\mathrm{Ln}\left(\mathrm{O}_{3}-\mathrm{P}\right.$ $\left.\mathrm{C}_{2} \mathrm{H}_{4}-\mathrm{SO}_{3}\right)(\mathrm{Ln}=\mathrm{Ho}, \mathrm{Er}, \mathrm{Tm}, \mathrm{Yb}, \mathrm{Lu}, \mathrm{Y})$. J. Solid State Chem. 2008, $181,3065-3070$.

(51) Feyand, M.; Näther, C.; Rothkirch, A.; Stock, N. Systematic and in situ energy dispersive $\mathrm{X}$-ray diffraction investigations on the formation of lanthanide phosphonatobutanesulfonates: $\mathrm{Ln}\left(\mathrm{O}_{3}-\mathrm{P}\right.$ $\left.\mathrm{C}_{4} \mathrm{H}_{8}-\mathrm{SO}_{3}\right)\left(\mathrm{H}_{2} \mathrm{O}\right)(\mathrm{Ln}=\mathrm{La}-\mathrm{Gd})$. Inorg. Chem. 2010, 49, 1115811163. 
(52) Du, Z.-Y.; Xu, H.-B.; Mao, J.-G. Rational Desing of 0D, 1D, and 3D open frameworks based on tetranuclear lanthanide(III) sulfonatephosphonate clusters. Inorg. Chem. 2006, 45, 9780-9788.

(53) Wong, N. E.; Ramaswamy, P.; Lee, A. S.; Gelfand, B. S.; Bladek, K. J.; Taylor, J. M.; Spasyuk, D. M.; Shimizu, G. K. Tuning intrinsic and extrinsic proton conduction in metal-organic frameworks by the lanthanide contraction. J. Am. Chem. Soc. 2017, 139, 14676-14683.

(54) Colomban, P.; Novak, A. Proton transfer and superionic conductivity in solids and gels. J. Mol. Struct. 1988, 177, 277-308.

(55) Kreuer, K. D. Proton conductivity: Materials and applications. Chem. Mater. 1996, 8, 610-641. 